\title{
Reconstruction in the Cotton Trade
}

\author{
By JoHn A. Todn, M.A. \\ Lecturer in Economics, Balliol College, Oxford, Author of The World's Cotton Crops, \\ Statistician to the World's Cotton Conference, 1921
}

T HE problem of reconstruction in the cotton trade is, in the writer's view, fundamentally a question of the supply of raw material, rather than of manufacturing capacity, or of the world's desire to consume, or power to pay for the goods. As will be seen from the tables annexed, the world's active spindleage today is substantially above pre-war figures, even after deducting the spindles in countries such as Russia, which are for the time being entirely out of commission; and the actual consumption of all kinds of cotton during the past season has been at the rate of 92.5 per cent of pre-war figures (1912-13), while the world's crops for 1921 were only about 70 per cent of those of 1912.

The problem of the raw material supply is not a new one in the cotton trade. As early as the beginning of the century those who took a long view of world conditions had become seriously alarmed about the prospects of supply in the future. The world's crops were increasing at a fairly rapid rate, but the potential demand for cotton was increasing still faster, and it was felt that the time might not be far distant when the point of actual scarcity would arrive. By 1914, this feeling had been considerably intensified on account of the development of the situation in the American Cotton Belt. Owing to the rising cost of production, particularly the increased labor cost, many of the planters were finding it difficult to make ends meet, especially in those years when, owing to a bountiful crop, prices were inclined to sag. As the possibility of diversification was increasing, even in those parts of the Belt which hitherto possessed no other money crop but cotton, the compulsion to grow cotton was lessened, with the result that cotton prices had developed a peculiar cycle. A big crop meant a lower price, which was promptly followed by a curtailment of the acreage in the following year. Other things being equal, this meant a short crop and a rise in price again. This state of afiairs was unquestionably bad for everyone concerned. The manufacturers and users of cotton had no sooner got accustomed to what they regarded as a reasonable level of prices, which enabled them to increase their output and spread their connections, when the rise of price checked business again. As a result of these conditions it was strongly felt in Lancashire that the world required not merely a steady increase of the total cotton supplies, estimated at about a million bales per annum, cumulative, but also that the new sources of supply should, as far as possible, be developed in other parts of the world where the labor supply would be cheaper, and, particularly, where the climatic variations would at least not be the same as those in the United States; so that a bad year in that part of the world might be set off by more favorable conditions elsewhere.

These pre-war conditions were intensified by the war. The first effect of the war in Europe was to cause a heavy fall of prices, which resulted 
in a sharp reduction of cotton acreage everywhere (except Russia) in 1915; and roughly speaking, this state of affairs continued in most cotton countries throughout the war, the world's supplies being reduced by about 20 per cent. On the suspension of hostilities it was hoped that there would be a quick return to normal production; but, unfortunately, the post-armistice slump again seriously discouraged the planters, and led to a comparatively small acreage in 1919. As it happened, the weather in the Southern States that year was, on the whole, unfavorable, especially during harvest time, and the crop was well down to the low average of the war-12,218,000 bales, including linters. The trade was therefore in a very bad position to meet the extraordinary increase of demand which broke over the whole world like a tidal wave during the winter of 1919-20. In the case of cotton goods, the difficulty was not primarily raw material, because, owing to the effects of the war and other disturbances, e.g., the devastated areas in France and Belgium, the revolution in Russia, the difficulty of getting raw material into enemy countries, and the reduction of the hours of labor through the general adoption of an eight-hour day, the world's capacity to produce cotton goods was substantially restricted. If it had been otherwise, and the manufacturers had been able to accept anything like the whole of the offers with which they were inundated, the world's available cotton supply would have been eaten up in six months; even as it was, the apparent approach of shortage sent cotton prices sky high, and levels were touched almost equal to the more or less mythical records of the cotton famine of the sixties, and the still higher levels of the early nineteenth century, due to the Napoleonic Wars and the consequent troubles between England and America.

When the slump came in the spring of 1920 , as the result of the adoption of a deliberate policy of deflation in the United States and Great Britain, the cotton trade was one of the first to feel the effects, and middling American cotton in New York fell from 43.75 cents in July, 1920, to 10.85 in June, 1921, which was well below pre-war prices. Once more the old vicious circle came into play. In 1921, the cotton acreage in the United States was again severely restricted, although there is, unfortunately, no certainty as to the extent of the reduction, owing to an extraordinary muddle with regard to the estimates of acreage. But it is clear that the acreage in 1921 was at least 18 per cent less than the figures touched in pre-war years $(30,509,000$ acres harvested, against $37,089,000$ in 1913), and from this area a crop of only $8,375,000$ bales (including linters) was gathered, being the smallest crop since 1895 , while the average yield per acre, 124.5 lbs., is the lowest on record. Yet even this unprecedented reduction of the supply failed to maintain a sufficiently high level of prices during the winter of 1921-22 to persuade the cotton planters to return to pre-war acreages in 1922. The reason was that, owing to the extraordinary strangulation of demand during the season 1920-21, there remained at the end of that season, an absolutely unprecedented world's carryover of American cotton of nearly ten million bales; while the ideas of the whole trade with regard to consumption had been brought down to such a low level that most people had ceased to consider the comparison with pre-war figures, and were inclined to think that the world had entered upon a new phase of poverty, as the result 
of which consumption could never again hope to touch pre-war levels. That idea, however, was quickly modified by the unexpected recovery of the demand during the season 1921-22. The International Federation statistics show that the world's total consumption of American cotton for the season was fully thirteen million bales (including linters), so that the excess of consumption over production had in one season wiped out the abnormal carryover of the previous season. Thus the results of one season, entirely abnormal in regard to demand, had been completely reversed by another, equally abnormal in regard to supply.

It would be out of place here to discuss the general arguments with regard to the policy of deflation; but the one aspect of that question which the writer desires to stress is that, so far as cotton was concerned, the fall of prices was certainly not due to the return of world conditions to a state of normal supply, though the fact of the 1920 crop being relatively large had helped in that direction. As a matter of fact the crop of 13,750,000 bales in that year was the largest since 1914, though still far short of pre-war record figures (17,000,000 bales in 1914). Unfortunately, instead of this recovery continuing, the 1921 crop provided the climax to the whole policy of restriction, and the question now is, what is going to happen in the future?

$\Lambda$ s regards the immediate future the question turns on the outcome of the 1922 crop. The acreage shows an increase of about 10 per cent, leaving it still distinctly short of pre-war records, but the season so far has been unfavorable, especially in one respect. The disastrously low average yield of the 1921 crop was due very largely to the depredations of the boll weevil; but it now appears that the damage due to this source may be at least as bad this year, and the fact has to be faced that the boll weevil has introduced an entirely new factor into the problem. This pest has now covered practically the whole Belt, and it has reduced the average yield from somewhere in the neighborhood of $200 \mathrm{lbs}$. per acre to something nearer 125. The consequences are extremely serious in more ways than one. Such a reduction of the yield per acre means not only a substantial reduction of the world's cotton supply, but it also means that the cost of production of the American crop, which still practically rules the world price of cotton, has been substantially raised. Before the war, the writer had calculated that, unless the price of cotton in New Orleans was about twelve cents a pound, it did not pay many of the growers, especially in Texas. It is impossible to say now what the corresponding figure would be under the changed conditions both of yield and cost of production; but probably somewhere about twenty cents would be nearer the trutb, and, even at that price, we cannot hope for an acreage more than pre-war, or a crop of much over ten million bales except in very favorable seasons. Had anyone predicted such a situation in the years before the war, he would have been regarded as a pessimist to the verge of lunacy.

Nor is there any material hope of relief from existing stocks. The world's carryover has now been reduced to about five million bales at the end of the season, as against about four million bales in pre-war times. There may, therefore, be still a small margin available to supplement the shortage of supply for this season, but that is all. It means, in effect, that this year's crop must be approximately sufficient to meet next winter's consumption. What then are 
the prospects with regard to the world's consumption in the immediate future?

On this point the trade is well supplied with statistical material. The International Federation for some time before the war had been providing fairly complete and reliable statistics of the consumption of cotton throughout the world, based on direct returns from the actual spinners in every country. As these returns cover a very large proportion of the world's total mill spindles, it is possible to estimate from them the total world's consumption of cotton of all kinds, and to compare these totals with the world's production of cotton in each season. This balance of production and consumption is shown in Table A, annexed. During the period of the war the Federation statistics, of course, could not be collected and the other sources used in this table must be taken with reserve; but it is possible to bridge over that gap in a way, by carrying on the statistics relative to American cotton alone, which are much less likely to be unreliable. This table brings out very clearly the extraordinary fluctuations in the balance, which swings heavily from excessive supply to excessive consumption; and it is very interesting to notice the effect on prices. For this purpose the season's average price of American cotton in Liverpool is given, and also (in order to get rid, as far as possible, of the effects of inflation) the same figures discounted by the general level of prices, as shown by the Board of Trade Index Numbers.

For the present, however, the most interesting point is to compare the post-war consumption with the prewar, and statistics for this purpose are given in Table B, showing separately the world's mill consumption of American cotton alone, and of all kinds. Roughly speaking, the result is as follows: during the boom of 1919-20 the world's consumption rose to about 83 per cent of the pre-war figures, the shortage being largely accounted for by the reduced hours of labor, but the distribution of the total throughout the world was very unequal. Great Britain was 82 per cent, the Continent only 41.6 per cent but America was 112 per cent and the rest of the world 114.5 per cent. In the following season, 1920-21, which covered the worst of the slump as well as the coal and cotton strikes in England, the world's total was 78.4 per cent. England being down to 47.4 per cent, while the Continent had risen to 60.3 per cent. The United States had fallen back to 85 per cent, but the rest of the world was now up to 126.2 per cent. But during the season now just closed, namely, to July 31, 1922, an extraordinary recovery was made, the world's total being 92.5 per cent, while England was 67 per cent and the Continent 68.0 per cent. The United States was 103.1 per cent whiie the rest of the world was 140.4 per cent. As a matter of fact, the figures of the second half year to July 31, 1922, were even better than those for the whole season, the improvement having been progressive throughout. From these figures, it will be seen that while the slump of 1920-21 very seriously affected the industry in Great Britain and the United States, the rest of the world was still going steadily ahead during that period. In other words, the countries which applied the doctrine of deflation had to suffer very severe trade depression, which did not affect the oriental countries to anything like the same extent, while most of Europe escaped any such depression by continuing more or less their policy of inflation. It remains then to apply these facts in the attempt to forecast the probable future. So far as England and 
the United States are concerned, the period of deflation is now apparently over, and, barring anything entirely unforeseen, they may be expected to continue the process of recovery which has been going on for the last twelve months. It must be remembered, too, that American consumption is now a good deal more than pre-war, their spindleage having been increased by 17.3 per cent since 1913. The position of India and Japan and other non-European countries is similar, their spindleage having been increased by 40 per cent $(4,982$,000 spindles); but this means a relatively large increase of consumption, because these countries use more bales of cotton per thousand spindles than any other countries in the world, and Japan and India are still laying down new spindles as fast as they can get them. India, particularly, is apparently determined to follow out the policy of protection of her local industry. As for the Continent of Europe, it is very probable that Germany and other countries in a similar position, where the industry has lately enjoyed a fictitious prosperity, will have to face a very bad time when their process of deflation or stabilization of currencies begins; but whether the consequent reduction of their consumption will be serious from the point of view of the world's total, it is difficult to say. As regards England, she has much to gain and probably something to lose from the developments which still lie in the future. It is very noticeable that during the past season her exports to India, first of yarns and then of piece goods, have shown a most astonishing recovery, but whether this is likely to continue or not, it would be very hard to say. On the whole, however, the probability is that England's consumption will not again sink below recent figures, unless prices rise high enough to check consumption seriously.

One other important country is Russia, where the consumption of cotton in pre-war days was very substantial, but statistics in Russia are now of almost no value. In any case, the importance of Russia's position in the world's consumption is greatly minimized by the fact that a considerable part of her consumption was local cotton grown in Transcaucasia and Russian Turkestan, and that crop has suffered, if anything, a more complete eclipse than the Russian cotton industry. The one, therefore, may be set against the other, and, practically speakîng, Russia might almost be excluded from the world's statistics. As it is, she is only credited in Table B with 1,100,000 active spindles, as against $9,213,000$ before the war.

To sum up, the recovery of the world's consumption during the past year has been much more rapid than any one expected, and the world is now consuming cotton at the rate of more than 90 per cent of the 1912-13 figures, while the production of cotton in 1921 was only at the rate of about 70 per cent, and this year is not likely to exceed 75 or 80 per cent of the 1912-13 crops. It does not need much arithmetic to realize that this is a state of affairs which cannot continue. If the world's crops do not, within the next year or two, make a very remarkable recovery from their recent low figures, then the world will simply be compelled to reduce its consumption by the fact that the cotton will not be there to consume! Then the old laws of supply and demand will have to settle the question again, and the price will have to rise to such a height as will limit the consumption to the supply available. He would be a bold man who would prophesy what that price will be. 
Reconstruction in the Cotton Trade

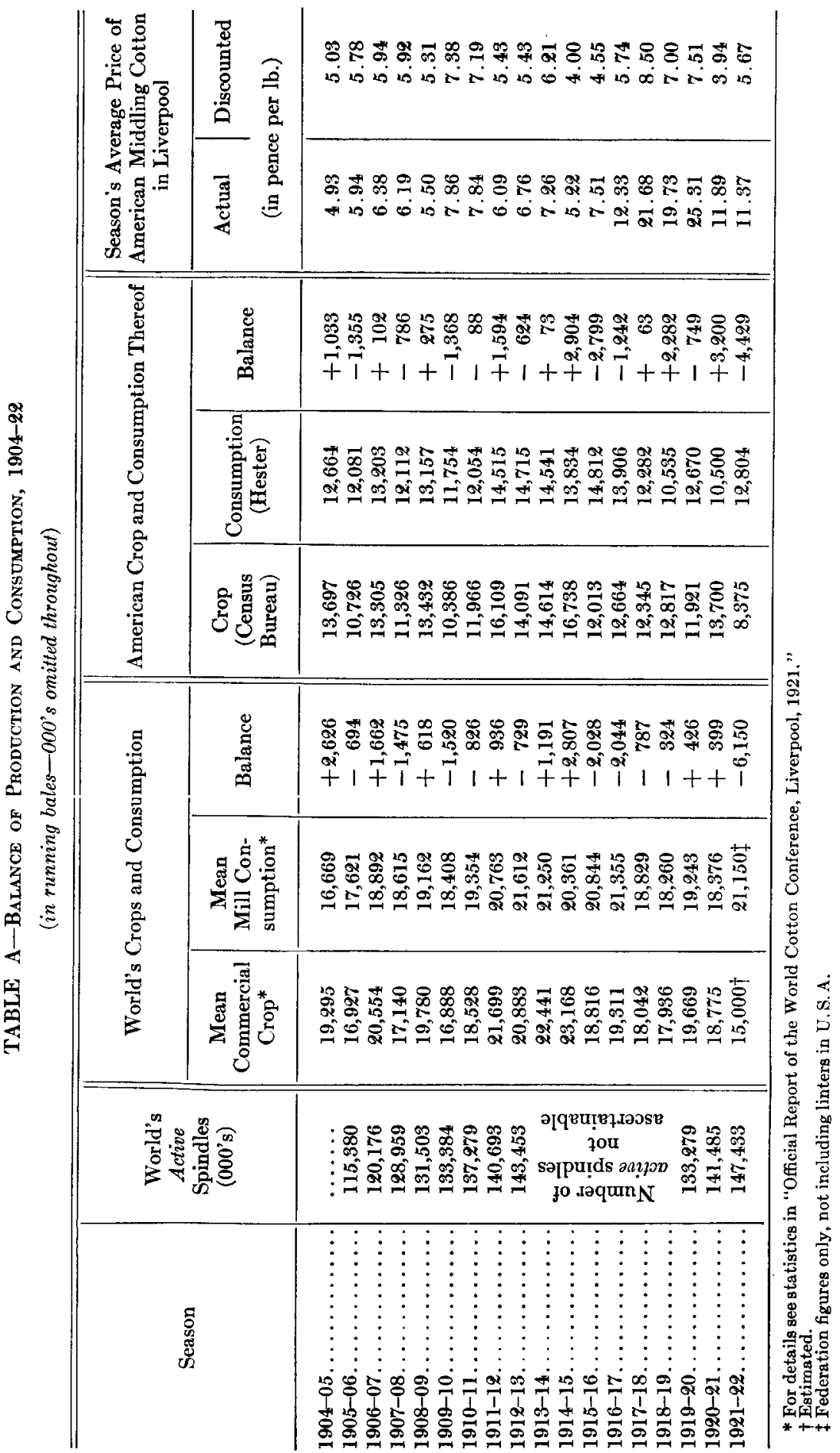




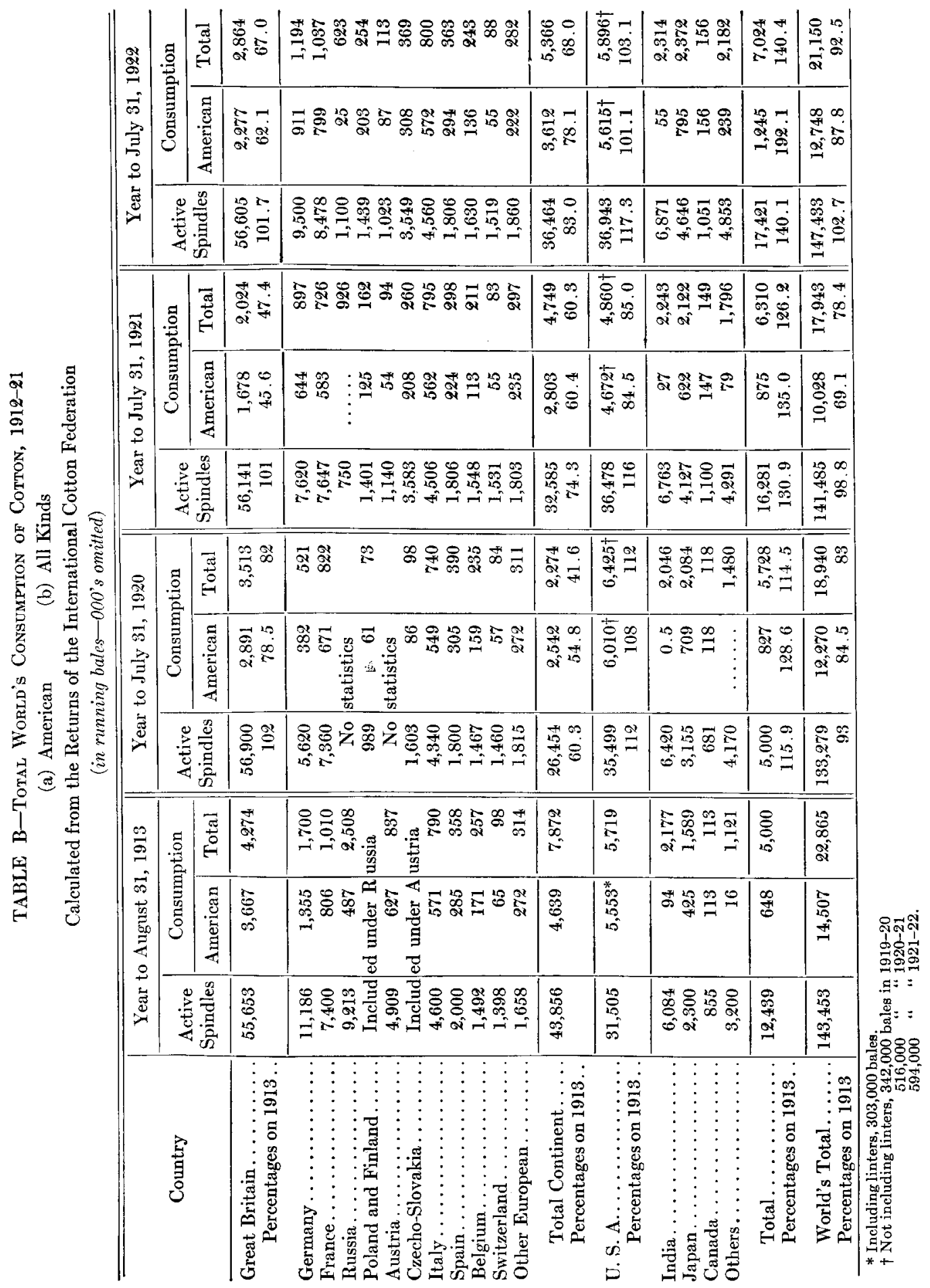

